significant change in the heart rate after treatment, as bradycardia is a common finding in hypothyroidism. The authors do not show their correction factor or the effect it had on the result.

Hammersmith Hospital,

J E SANDERSON

1 Tavel, M E, et al, British Heart fournal, 1965, 27, 829 ' Prewitt, T, et al, British Heart fournal, 1975, 37, 1256 . Clinical Research, 1973, 21, 446.

\section{Accidents on holiday}

SIR,-Mr M J Merlin's letter (3 July, p 42) highlights a problem which should be avoidable by good communications. It would be ethical to refer back to the general practitioner at home a patient who is treated for an injury on holiday, but prompt action by the GP can be frustrated if an outpatient appointment request disappears into the appointments machinery owing to somebody's failure to appreciate its urgency. It is not unknown for someone to come to a clinic for the first time with a fracture which has become redisplaced in a plaster cast and which has united too far to permit remanipulation.

Hospital operational plans vary, but one common feature is a trauma flow pattern starting at the accident department door. The surest procedure, therefore, is to write a full letter to the senior accident surgeon of the most convenient accident department for the patient, preferably naming the hospital. A copy is posted to the general practitioner at home, who is thus kept informed and can monitor progress. The letter itself is included with the $x$-rays and given to the patient to be taken in person to the accident department without fail the morning after arrival in his home district.

The only problem I have met from this is the understandable objection of the $x$-ray department to the loss of its films. The radiologists are naturally concerned at the possibility of missing a diagnosis through inability to report on the films and at the trouble caused if $x$-rays are unaccounted for when needed again. However, this can be overcome if the $x$-ray department is informed promptly whenever $x$-rays are sent out of the hospital.

Roger Mangnali

Bury St Edmunds,

Surfolk

\section{Vitamin A and lung cancer}

SIR,-In a recent leading article (3 July, p 2) the background to the possible cancer preventive value of vitamin $A$ is discussed. Thi has consisted mainly of laboratory work both in vitro and in animal experiments. In man there has previously been only one study, of an epidemiological nature, which associated bronchial carcinoma with a low dietary intake of vitamin A.

My colleagues and I have recently carried out a small pilot study ${ }^{2}$ and reported 28 patients suffering from bronchial carcinoma who were found at the time of diagnosis to have significantly lower plasma levels of vitamin A than a control group of 10 healthy subjects and nine patients with non-malignan bronchial disease. Among these 28 bronchial carcinoma cases the plasma vitamin A levels were significantly lower in those with oat-cell and squamous-cell histology than in those with the undifferentiated large-cell variety. The implications of these findings remain obscure at the present time.

However, in this context it is of interest to recall the findings of Dijkstra, ${ }^{3}$ who demonstrated a high incidence of bronchial carcinoma in those born in the winter months in Holland. He attempted to explain this by the following hypothesis. The fetus at birth has low levels of vitamin $A$. In the winter months the level of vitamin A in cow's milk is at its lowest. If the newborn infant is fed on cow's milk its vitamin A level remains low at the critical period when the lung is beginning to function and active bronchial development is proceeding. As a result of this vitamin A deficiency the bronchial mucosa may undergo squamous metaplasia and this later predisposes the individual to bronchial carcinoma when subjected to further bronchial insult (for example, by smoking).

If the bronchial damage by vitamin A deficiency has taken place at such an early stage it is unreasonable to expect success from the US National Cancer Institute's trial of added vitamin $A$ for smoking adults in the hope that it will prevent the development of bronchial carcinoma.

Although successful prophylaxis with vitamin A remains to be proved, there is some evidence to suggest that vitamin $\mathrm{A}$ in high doses may have a part to play in the treatment of bronchial carcinoma, especially of squamous-cell type.

Redhill General Hospital,

Alex SAKULA

Redhill, Surrey

' Bjelke, E, International Fournal of Cancer, 1975, 15, 'Basu, T K, et al, British fournal of Cancer, 1976, 33, 119.
1 iikstra, B K S, fournal of the National Cancer Diikstra, B K S, Fournal

Micksche, M, et al, OSterreichische Zeitschrift für
Onkologie, 1974, 3,70.

\section{Urinary retention in women}

SIR,-A cause of urinary retention in women not specifically mentioned in your leading article (26 June, p 1554) is primary genital infection with Herpesvirus hominis. This can cause extensive oedema and ulceration of the vulva and introitus. Many patients with herpes have some degree of dysuria, but in particular if periurethral ulceration is present the symptoms are very distressing.

In this clinic two patients with acute retention due to genital herpes have been seen during the past three years. Others, we believe, have avoided this complication with the help of simple advice-for example, to pass urine while standing or sitting in a cool bath. As this infection is now being seen more frequently the incidence of retention of urine in young women is likely to increase.

E BARBARA TURNER

Special Clinic,

Royal Infirmary,

Sheffield

\section{Outpatient laparoscopic sterilisation}

SIR,-At a time when the hospital service is forced to wear an ever-tightening financial strait-jacket one can only applaud the spirit and the contents of $\mathrm{Mr} \mathrm{J} \mathrm{H}$ Brash's article (5 June, p 1376). It is to be hoped therefore, that not too much emphasis will be placed on the dire warnings contained in the letter from Major R H Jago (3 July, p 46).

In contrast to that of Major Jago my own experience does not bear out the view that controlled ventilation with endotracheal intubation is mandatory-or even desirable-in anaesthesia for laparoscopic sterilisation. I would venture to suggest that the anaesthetic technique used for the patients in Mr Brash's series is entirely suitable in the circumstances and, indeed, completely eliminates the possibility of such inconveniences as postoperative tracheitis or pharyngitis, damage to teeth or lips, etc.

But even more contentious is the statement in the last paragraph of Major Jago's letter that "the use of muscle relaxants is contraindicated in day-case anaesthesia." Few if any anaesthetists with experience in this field would concur in that view.

T R M BRISTOW

Royal Berkshire Hospital,

Reading

\section{Incidence of dermographism}

SIR,-I was very interested to read the letter from $\operatorname{Dr} R \mathrm{~F} Q$ Johnson on this subject (19 June, p 1533). It has been difficult to get a simple machine giving different pressures. Various devices have been described in the literature but a useful and inexpensive one was described by Bettley ${ }^{1}$ and modified by Kirby et al. ${ }^{2}$ This machine can now be ordered from: Hook and Tucker Instruments Ltd Vulcan Way, New Addington, Croydon CRO 9UG. The incidence of dermographism is discussed by Kirby et $a l^{2}$ and the whole subject by Warin and Champion."

There are a number of different types of dermographism, but there are two common patterns. The first is simple dermographism, occurring in some $5 \%$ of the population with the same incidence throughout all age groups, and this may well be just a physiologica variant. The second pattern is symptomatic dermographism, seen most commonly in young adults and associated with considerable itching; the outlook is good, and many cases settle down after a few months or years. There is an immunological basis for this second pattern and it can be transferred by the IgE immunoglobulin to the skin of a normal subject.

Less common types of dermographism include those occasionally following an attack of acute urticaria, occurring at the site of urticaria pigmentosa, and where there has been a previous allergic reaction in the skin There is a form of delayed dermographism and one where the skin urticates on rubbing rather than scratching, producing a diffuse redness, stippled with tiny weals (cholinergic dermographism). This last type can sometimes be demonstrated in cholinergic urticaria but may occur on its own and be the cause of a widespread pruritus. The incidence of dermographism in chronic urticaria is probably no greater than in a series of control patients.

R P WARIN Bristol

Bettley, F R, fournal of Investigative Dermatology, 1962, 39, 1.
Kirby, J D, al, British fournal of Dermatology
1971, 85, 331. Warin, R P, and Champion, R H, Urticaria. London,
Saunders, 1975 . 